\title{
Pedagogia do MST: uma construção com a presença de Paulo Freire
}

\author{
Ana Maria Baldo ${ }^{1}$ \\ Orcid: https://orcid.org/0000-0002-7973-1345 \\ Elisete Enir Bernardi Garcia ${ }^{2}$ \\ Orcid: https://orcid.org/0000-0002-1211-3059
}

\begin{abstract}
Resumo
O presente artigo, de natureza bibliográfica, excerto de dissertação de Mestrado em desenvolvimento, visa analisar a presença da perspectiva freiriana na pedagogia do Movimento dos Trabalhadores e Trabalhadoras Rurais Sem Terra - MST. Nas análises parciais obtidas, podemos perceber que a pedagogia do MST está fundamentada, em grande medida, nesta perspectiva. A experiência do Movimento Sem Terra com sua pedagogia nos mostra caminhos viáveis e concretos para uma educação voltada para a transformação social e a emancipação humana. Freire deixou um forte legado para a construção da pedagogia do MST, sendo um de seus maiores inspiradores; o MST, do mesmo modo, afirma ter herdado características importantes da pedagogia freiriana, bem como ter em Freire, além de um inspirador, um companheiro de luta. Há uma relação recíproca de ideias, sonhos, afeto e utopias.
\end{abstract}

Palavras-chave: Movimentos Sociais. Paulo Freire. Educação Libertadora.

\begin{abstract}
The present article, of bibliographic nature, excerpt from a Master's thesis in development, aims to analyze the presence of the Freirean perspective in the pedagogy of the Landless Rural Workers Movement - MST. In the partial analyzes obtained, we can see that the pedagogy of the MST is based, to a large extent, on this perspective. The experience of the Landless Movement with its pedagogy shows us viable and concrete paths towards an education focused on social transformation and human emancipation. Freire left a strong legacy for the construction of the MST pedagogy, being one of its greatest inspirers; the MST, likewise, claims to have inherited important characteristics of Freire's pedagogy, as well as having in Freire, in addition to being an inspirer, a companion in the struggle. There is a reciprocal relationship of ideas, dreams, affection and utopias.
\end{abstract}

Keywords: Social movements. Paulo Freire. Liberating Education.

\footnotetext{
${ }^{1}$ Graduada em História - Licenciatura Plena pela Universidade Regional do Alto Uruguai e das Missões - URI. Mestranda do Programa de Pós-Graduação Mestrado Profissional em Educação da Universidade Estadual do Rio Grande do Sul - UERGS Osório - RS - Brasil. Filiação: Universidade Estadual do Rio Grande do Sul - UERGS - Osório - RS - Brasil. E-mail: anabaldo@uergs.edu.br

${ }^{2}$ Graduada em Pedagogia; Especialista em Educação Profissional Técnica de Nível Médio na Modalidade de Educação de Jovens e Adultos - PROEJA - Universidade Federal do Rio Grande do Sul - UFRGS; Mestrado em Educação pela Universidade do Vale do Rio dos Sinos - UNISINOS; Doutorado em educação pela UNISINOS. Filiação: Universidade Federal do Rio Grande do Sul - UFRGS - Porto Alegre - RS - Brasil. E-mail: elisete.bernardi@gmail.com
} 


\section{Introdução}

O presente artigo está vinculado à dissertação desenvolvida no Programa de PósGraduação do Mestrado Profissional em Educação da Universidade Estadual do Rio Grande do Sul - UERGS, intitulada Pedagogia do MST: contribuições para a escola pública de Educação Básica, na linha de pesquisa: Currículos e Políticas na Formação de Professores. As análises parciais que obtivemos nos possibilitaram compreender de que modo a pedagogia do MST desenvolveu-se com base, principalmente, na perspectiva de Paulo Freire e em sua concepção de educação. Pretendemos aqui realizar uma breve contextualização da construção do Movimento Sem Terra, visando evidenciar o caráter central dado pelo MST à educação, definindo-a como base para a construção do ideário do Movimento na busca pela transformação social e pela emancipação humana.

O Movimento dos Trabalhadores e Trabalhadoras Rurais Sem Terra - MST teve sua gestação no período de 1979-1984, e foi criado formalmente em seu Primeiro Encontro Nacional, que ocorreu em janeiro de 1984, na cidade de Cascavel, no estado do Paraná. O MST surge sintetizando as lutas anteriores dos camponeses e trabalhadores rurais, unindo diversos conflitos regionais, agregando forças, com caráter nacional e com o pressuposto básico da autonomia. E para que sua luta pela transformação social pudesse obter êxito, o Movimento reconheceu que seria necessário criar uma proposta pedagógica, ou uma pedagogia mesma, que levasse em conta as especificidades do sujeito Sem Terra e seu propósito para além da Reforma Agrária.

A pedagogia do MST se estrutura como uma pedagogia da emancipação humana, da transformação social, da percepção da opressão. O MST busca com essa pedagogia criar nos sujeitos Sem Terra ${ }^{3}$, e através deles, a consciência da exclusão e da opressão a que estes estão submetidos e, partindo dessa consciência, alterar a sociedade rumo a uma nova forma de existir e estar no mundo.

Como procedimento metodológico adotamos a pesquisa bibliográfica e documental, a partir de levantamento e revisão da literatura, publicações existentes sobre o tema, e pesquisa eletrônica em sites e homepages relacionados à temática pesquisada. Sendo assim, buscaremos neste artigo evidenciar a presença da perspectiva freiriana na pedagogia do MST, bem como a relação existente entre o Movimento Sem Terra e Paulo Freire. Freire deixou um forte legado para a construção da pedagogia do MST, sendo um de seus maiores inspiradores. O MST reconhece ter herdado da pedagogia freiriana características importantes, bem como ter em Freire, além de um inspirador, um companheiro de luta; há uma relação recíproca de ideias, sonhos, afeto e utopias.

\footnotetext{
${ }^{3}$ Gostaríamos aqui de fazer um esclarecimento acerca da utilização do termo Sem Terra. Comumente se usa o termo sem-terra, em letras minúsculas e com hífen para designar aqueles que não tem acesso ou a propriedade da terra, ou seja, o camponês e camponesa que não possui terra. Já o termo que empregamos aqui "Sem Terra" com iniciais maiúsculas e sem o uso do hífen, enquanto nome próprio, como designação de um sujeito que pertence ao Movimento dos Trabalhadores e Trabalhadoras Rurais Sem Terra, seja ele sem-terra acampado aguardando a Reforma Agrária, seja ele um assentado já proprietário de seu pedaço de chão, representando seu pertencimento à luta coletiva do MST. O Sem Terra é aqui uma identidade. Esclarecemos também que sempre que nos utilizarmos do termo Movimento, com a inicial maiúscula estaremos nos referindo ao MST. Esses conhecimentos foram adquiridos pela pesquisadora no tempo em que residiu no Acampamento Oziel Alves, do MST, no munícipio de Sarandi no Rio Grande do Sul. Mais esclarecimentos acerca dessa nomenclatura podem ser encontrados em: CALDART, Roseli. Pedagogia do Movimento dos Sem-Terra. Petrópolis: Vozes, 1999.
} 


\section{O MST: Para além da luta pela terra, uma pedagogia}

Tendo por objetivo equacionar os conflitos envolvendo a posse da terra no Brasil, o Movimento Sem Terra é criado visando, primeiramente, a Reforma Agrária vinculada à transformação estrutural da sociedade. O Movimento estabelece-se do conflito dos sem-terra com a realidade social em que viviam, no momento em que os mesmos tomam consciência e se organizam como um movimento social. Movimento este em que o modelo agrário é permanentemente questionado e que o intuito de permanecerem como agricultores familiares é constantemente reafirmado. Seu sentido político de luta, segundo Poli (1999, p. 120):

[...] não decorre das relações mais imediatas que eles mantêm, mas do fato de porém a nu sua situação comum de excluídos, devido à estrutura agrária vigente e de exigirem do Estado medidas que lhes garantam o acesso à propriedade da terra e sua reintegração econômica e social como pequenos proprietários.

A percepção por parte do Movimento de que a causa que gerou o problema agrário dos sem-terra estava estritamente ligada ao modelo agrícola, baseado na agroindústria e voltado para a exportação, levou o MST a reivindicar não apenas a Reforma Agrária, mas uma mudança estrutural da sociedade (MST, 2001). De tal modo, as pressões que levaram os trabalhadores e trabalhadoras do campo a se organizarem em um movimento foram criadas a partir da situação econômica e social originada pelas políticas agrícolas que transformaram a agricultura na década de 1970, especialmente na região sul do Brasil (POLI, 1999). Como resultado dessas novas transformações no campo viu-se uma crescente afirmação social criando novos interesses e a necessidade de novas formas de representação. Poli (1999, p. 34) afirma que

Sua participação (dos camponeses) se dava sempre por via indireta, através dos coronéis ou dos padrinhos, figuras centrais na sustentação do poder instituído, aos quais serviam de massa de manobra. Essa falta de uma representatividade, própria e autônoma, nos canais instituídos de representação política, é marcante na história política do campesinato brasileiro.

O MST se concebe, assim, como um movimento de grande destaque por permitir à massa camponesa se libertar da falsa ideia de igualdade e de proximidade entre as diferentes classes presentes na estrutura social, criada através do compadrio, do apadrinhamento, estes que impossibilitavam ao camponês a construção de uma identidade de grupo marginalizado (POLI, 1999). Para Poli “o MST representa um grande salto de qualidade na luta pela reforma agrária no Brasil", destacando "a sua maturidade política, no sentido de decidir de forma serena e planejada as táticas adequadas a cada momento" (POLI, 1999, p. 118).

Poli $(1999$, p. 119) ainda ressalta a participação ativa dos camponeses na luta pela terra.

Esse parece ser mesmo, dentro da história da participação política do campesinato brasileiro, o grande salto de qualidade que o MST representa. Os próprios camponeses se capacitando a assumir diretamente a condução de sua organização e de suas lutas, e, fazendo isso, não de uma forma espontaneísta ou calcada em reações de caráter emocional ou de fanatismo religioso. Ao contrário, fazem-no de forma refletida, serena e planejada, a partir de uma certa compreensão da realidade social, econômica e política e, sobretudo, fundiária brasileira (Grifos nossos).

Assim, o MST se fez um movimento politicamente autônomo, capacitado a intervir nos meios necessários conforme os seus interesses sem a necessidade de representantes externos ao grupo, podendo recorrer a instituições políticas, mas sem atrelar-se a elas. Uma das vias para 
alcançar esse objetivo de ser politicamente autônomo é a educação dentro do Movimento, que contribui para a construção de um novo modo de ser e agir enquanto sujeito Sem Terra, dentro de uma proposta de construção de uma nova sociedade. Reck (2005, p. 109) afirma que no caso do MST

[...] as lutas não podem ser vistas como uma simples reação à falta de terras, se assim fosse ela seria resolvida com a simples distribuição de terras para os trabalhadores rurais; porém, o caráter conflituoso do movimento MST, de acordo com nosso conhecimento a priori do seu ideário, caracteriza-se pelo questionamento da lógica do próprio sistema capitalista. Por isso, fica evidente o caráter antagônico de sua ação questionando a legitimidade do próprio poder.

Percebemos assim que o Movimento Sem Terra visa à transformação social e econômica e não apenas a conquista da terra em si; busca uma nova forma de sociedade e de sujeito, um novo homem e uma nova mulher em uma sociedade justa e igualitária. Para isso, o MST (2001), entende que a educação é o meio mais viável e apropriado para alcançar esses objetivos; somente através dela e da luta social poderão construir um novo sujeito e uma nova estrutura social e econômica.

Desse modo o MST criou sua própria pedagogia, uma pedagogia singular. E o Movimento reafirma que não se trata mais de uma proposta pedagógica e sim de uma pedagogia. O MST destaca em seus documentos referentes à educação que possui uma Pedagogia, que "é o jeito através do qual o Movimento historicamente vem formando o sujeito social de nome Sem Terra, e que no dia a dia educa as pessoas que dele fazem parte" (MST, 2005 , p. 200). E o princípio educativo principal desta pedagogia é o próprio Movimento. O MST questiona "por que falar em Pedagogia do Movimento Sem Terra e não mais em proposta de educação ou proposta pedagógica do MST? (Ibid., p. 235). Esse questionamento é respondido pelo próprio MST (2005, p. 235) que afirma que "a pedagogia do MST hoje é mais do que uma proposta. É uma prática viva, em movimento".

Vários pensadores e pedagogos foram estudados pelo MST visando formar a base dessa pedagogia própria, como Pistrak, Makarenko e José Martí. Entretanto, pode-se perceber a perspectiva freiriana presente de forma muito mais enfática em praticamente todos os aspectos da pedagogia do MST. Segundo Dalmagro (2010, p. 210)

A Pedagogia Socialista parece ter sido importante no momento de pensar a forma da escola, (trabalho, organização estudantil, tempos educativos); já Freire teve um peso maior quando da definição do método de estudo, a consideração da realidade do educando, o universo local como ponto de partida, entre outras temáticas. Nas escolas que se orientam na proposta de educação do MST a influência de Paulo Freire, cujos temas geradores são referência fundamental, mostra-se bem mais vigorosa.

Nesse sentido, Gonsaga (2008, p. 7) afirma que

O MST, partindo do princípio da pedagogia libertadora, vem lutando para implementar uma proposta de educação que vai de encontro ao modelo tradicional proposto, uma educação que atenda às suas reais necessidades, que proporcione aos seus educandos uma formação mais global onde eles aprendam a ler, escrever e analisar a realidade. Vale lembrar que, para Paulo Freire, a consciência política é condição básica para o educador na pedagogia libertadora, sem a qual se torna difícil para o mesmo se posicionar politicamente frente às desigualdades estruturais da sociedade. 
Nessa mesma linha de pensamento, Brito et al. (2008), afirma que a contribuição freiriana no MST é percebida na adoção de uma prática educacional em que as crianças estudam para se formarem sujeitos analisando a realidade que os cerca, e conscientes de seu papel dentro do Movimento e na luta pela transformação social. Segundo os autores "trata-se de uma Educação para liberdade, [...] é o método educacional adotado que irá formar estes sujeitos aptos a questionarem uma ordem instalada percebendo-a enquanto opressora, para assim libertar-se" (BRITO et al., 2008, p. 2). Entretanto, os autores salientam que, apesar da influência e das similaridades com a perspectiva freiriana, o MST possui uma pedagogia singular e própria. "Sendo assim temos uma contribuição indiscutível da Pedagogia Freiriana, para a construção de uma Pedagogia singular do Movimento dos Trabalhadores e Trabalhadoras Sem Terra" (BRITO et al., 2008, p. 6). A pedagogia do MST, mesmo sendo uma pedagogia própria e singular, se desenvolve na perspectiva de uma educação emancipatória, transformadora e libertadora, seguindo os pensamentos de Paulo Freire, onde os educandos e educandas são sujeitos ativos no seu processo de ensino-aprendizagem e se percebem enquanto tais.

Além disso, através das leituras de artigos, cartas pedagógicas e mensagens de Freire, enviadas ao MST, podemos perceber que há uma relação de reciprocidade na troca de aprendizagens, conhecimentos e afeto entre ambos. Em seu Boletim de Educação número 15 intitulado Paulo Freire e a pedagogia do trabalho popular, o MST (2020), afirma que

Na sua trajetória de educador, Paulo Freire nos deixou um legado muito importante: $1^{\circ}$ ) uma profunda crença na pessoa humana e na sua capacidade de educar-se como sujeito da história; $2^{\circ}$ ) uma postura política firme e coerente com as causas do povo oprimido, temperada com a capacidade de sonhar e de ter esperanças, e com a ousadia de fazer e de lutar pelo que se acredita. E, junto com isto, a humildade de quem sabe que nenhuma obra grandiosa se faz sozinho, e que é preciso continuar aprendendo sempre; $3^{\circ}$ ) um jeito do povo se educar para transformar a realidade. Uma pedagogia que valoriza o saber do povo, ao mesmo tempo que o desafia a saber sempre mais; $4^{\circ}$ ) uma preocupação especial com a superação do analfabetismo, e com uma pedagogia que alfabetize o povo para ler o mundo. Conhecer, dialogar e conviver com o legado de Paulo Freire nos ajuda a refletir sobre nossa prática, e a crescer em nossa identidade de Sem Terra, de classe trabalhadora, de povo brasileiro.

Através dessa afirmativa do MST percebemos de forma evidente a presença de Freire na construção da pedagogia do MST; o Movimento demonstra ter presente em seu ideário o legado de Freire.

Quanto a Freire, em 1968, exilado no Chile, escrevia as seguintes linhas sobre o processo de reforma agrária chileno e a estrutura latifundiária, que em muito se assemelha à brasileira. Freire (2001, p. 35) afirma que

Incidindo sobre a estrutura do latifúndio, transformando-a noutra, transitória, a do "asentamiento", a reforma agrária exige um permanente pensar crítico em torno da ação transformadora mesma e dos resultados que dela se obtenham. Qualquer postura ingênua em face deste processo, da qual resultem quefazeres igualmente ingênuos, pode conduzir a erros e a equívocos funestos. Um desses equívocos, por exemplo, pode ser o de reduzir a ação transformadora a um ato mecânico, através do qual a estrutura do latifúndio cederia seu lugar à do "asentamiento", como quando alguém, mecanicamente, substitui uma cadeira por outra, ou a desloca de um lugar a outro. 
Freire demonstra assim possuir interesse na temática da Reforma Agrária e das lutas sociais e camponesas, valorizando a sabedoria e a cultura do camponês. E Freire (2001, p. 36) segue sua explanação destacando que

Subestimar a capacidade criadora e recriadora dos camponeses, desprezar seus conhecimentos, não importa o nível em que se achem, tentar "enchê-los" com o que aos técnicos, lhes parece certo, são expressões, em última análise, da ideologia dominante. Não queremos, contudo, com isto dizer que os camponeses devam permanecer no estado em que se encontram com relação a seu enfrentamento com o mundo natural e à sua posição em face da vida política do país. Queremos afirmar que eles não devem ser considerados como "vasilhas" vazias nas quais se vá depositando o conhecimento dos especialistas, mas, pelo contrário, sujeitos, também, do processo de sua capacitação.

Podemos perceber que o MST, desde sua criação em 1984, teve essa visão acerca da reforma agrária e dos camponeses. Uma visão de que a reforma agrária só seria possível através do enfrentamento ao latifúndio e do respeito e valorização do conhecimento já produzido pelos camponeses. Seguindo os ensinamentos de Freire (2001, p. 37) que dizia que

Imobilizar os camponeses exercendo ainda sobre eles uma prática assistencialista, não pode constituir-se no caminho para tal superação. Por este caminho, os camponeses poderão ser, no máximo, incorporados como objetos ao processo da reforma agrária, jamais a ele incorporados como sujeitos dele. Podem ser incorporados à produção, como instrumentos dela, jamais incorporar-se a ela como sujeitos.

Aqui encontramos uma relação entre Freire e MST, que Poli (1999) descreve como a permissão aos camponeses e camponesas de liberdade da falsa ideia de igualdade e de proximidade entre classes, permitindo à massa camponesa criar a identidade de grupo oprimido. Freire (1983) afirma que a reforma agrária, como um processo global, não pode limitar-se à ação unilateral no domínio das técnicas de produção, de comercialização etc., mas, "pelo contrário, deve unir este esforço indispensável a outro igualmente imprescindível: $o$ da transformação cultural, intencional, sistematizada, programada" (POLI, 1999, p. 57, grifos nossos).

Ao dar seu depoimento aos educadores e educadoras do $\mathrm{MST}^{4}$, em 1996, Freire (2020a, p. 111-112) afirma que

a prática educativa tem que estar vinculada à questão da produção, tem que estar vinculada à questão da cultura, tem que estar vinculada à história. No fundo, o processo de reforma agrária inaugura uma nova história dos homens e das mulheres. Inaugura uma nova cultura, a cultura que nasce de um processo de transformação do mundo, e por isto mesmo, ela implica em transformações sociais (Grifos nossos).

Nesse mesmo depoimento Freire (2020a., p. 112) demonstra sua certeza de que a luta pela reforma agrária e pela transformação social são indissociáveis:

\footnotetext{
${ }^{4}$ Este texto é uma transcrição do depoimento de Paulo Freire, gravado em vídeo, para os educadores e as educadoras do MST, em novembro de 1996. Texto publicado no Caderno Paulo Freire: um educador do povo. Iterra, 2001, p. 38-40; e posteriormente publicado em MST. Paulo Freire e a pedagogia do trabalho popular. Boletim da Educação n 15. São Paulo: 2020.
} 
Então, trabalhar no sentido de ajudar os homens e mulheres brasileiros a exercer o direito de estar de pé, no chão, cavando e retificando o chão, fazendo com que o chão produza melhor, é um direito e um dever nosso. E a educação é uma das portas, ou é uma das chaves para abrir estas portas. Eu nunca me esqueço de uma frase linda de um educador, alfabetizador, um camponês Sem Terra, de um assentamento enorme no Rio Grande do Sul, aonde eu fui: "um dia pela força de nosso trabalho e de nossa luta cortamos os arames farpados do latifúndio e entramos nele, mas quando nele chegamos, descobrimos que existem outros arames farpados, como o arame da nossa ignorância. E então ali eu percebi, melhor ainda naquele dia, que quanto mais ignorante, quanto mais inocentes diante do mundo, tanto melhor para os donos do mundo, e quanto mais sabido, no sentido de conhecer, tanto mais medrosos ficarão os donos do mundo. Então eu acho que isto não é uma tarefa só política, que não é só ideológica, e que sendo política e ideológica é, sobretudo, pedagógica. Não há reforma agrária sem isto... (Grifos nossos).

Em Pedagogia da Indignação, ao escrever sobre $O$ direito e o dever de mudar o mundo, Freire (2019, p. 62-63) demonstra mais uma vez sua relação de afeto com o Movimento Sem Terra, ao afirmar que

Neste sentido é tão atual o ímpeto de rebeldia contra a agressiva injustiça que caracteriza a posse da terra entre nós, de maneira eloquente, encarnado pelo Movimento dos Trabalhadores Sem Terra quanto a reação indecorosa dos latifundistas, muito mais amparados, obviamente, por uma legislação a serviço preponderantemente de seus interesses, a qualquer reforma agrária, por mais tímida que seja. A luta pela reforma agrária representa o avanço necessário a que se opõe o atraso imobilizador do conservadorismo.

E Freire (2019, p. 69-70) na sequência de sua escrita corrobora e enfatiza essa ideia ao afirmar que

O Movimento dos Sem Terra, tão ético e pedagógico quanto cheio de boniteza, não começou agora, nem há dez ou 15, ou 20 anos. Suas raízes mais remotas se acham na rebeldia dos quilombos e, mais recentemente, na bravura de seus companheiros das Ligas Camponesas que há quarenta anos foram esmagados pelas mesmas forças retrógradas do imobilismo reacionário, colonial e perverso. O importante porém é reconhecer que os quilombos tanto quanto os camponeses das Ligas [Camponesas] e os Sem Terra de hoje, todos em seu tempo, anteontem, ontem e agora sonharam e sonham o mesmo sonho, acreditaram e acreditam na imperiosa necessidade da luta na feitura da história como "façanha da liberdade". No fundo, jamais se entregariam à falsidade ideológica da frase: "a realidade é assim mesmo, não adianta lutar". Pelo contrário, apostaram na intervenção no mundo para retificá-lo e não apenas para mantê-lo mais ou menos como está. Se os Sem Terra tivessem acreditado na "morte da história", da utopia, do sonho; no desaparecimento das classes sociais, na ineficácia dos testemunhos de amor à liberdade; se tivessem acreditado que a crítica ao fatalismo neoliberal é a expressão de um "neobobismo" que nada constrói; se tivessem acreditado na despolitização da política, embutida nos discursos que falam de que o que vale hoje é "pouca conversa, menos política e só resultados", se, acreditando nos discursos oficiais, tivessem desistido das ocupações e voltado não para suas casas, mas para a negação de si mesmos, mais uma vez a reforma agrária seria arquivada. 
E Freire (2019, p. 70) conclui esses escritos afirmando que

A eles e elas, Sem Terra, a seu inconformismo, à sua determinação de ajudar a democratização deste país devemos mais do que às vezes podemos pensar. E que bom seria para a ampliação e a consolidação de nossa democracia, sobretudo para sua autenticidade, se outras marchas se seguissem à sua. A marcha dos desempregados, dos injustiçados, dos que protestam contra a impunidade, dos que clamam contra a violência, contra a mentira e o desrespeito à coisa pública. A marcha dos sem-teto, dos sem-escola, dos semhospital, dos renegados. A marcha esperançosa dos que sabem que mudar é possível. (Grifos nossos)

As citações aqui apresentadas se fazem necessárias para que, além de demonstrar a reciprocidade existente entre MST e Freire, tragam para este artigo a beleza das palavras de Freire sobre o Movimento Sem Terra e sua luta contra o latifúndio e a opressão a que o povo camponês é submetido.

Quanto à presença de Freire no Movimento Sem Terra, a educação do MST está impregnada dela, demonstrando assim a harmonia existente entre eles. Vemos isso nas afirmações do MST (2020, p. 149-150) que destaca:

Aprendemos com Paulo Freire a importância de confiar no povo e numa educação que o transforme em sujeito de sua própria libertação [...] A Pedagogia do Movimento pode ser considerada uma das herdeiras da Pedagogia do Oprimido, porque a realiza na prática e na teoria da formação dos Sem Terra do MST [...] Com Paulo Freire compreendemos ainda melhor que ninguém liberta ninguém e ninguém se liberta sozinho; as pessoas se libertam em comunhão. E é por isso também que ninguém educa ninguém, ninguém se educa sozinho; as pessoas se educam em comunhão, mediatizadas pelo mundo, pela realidade social em que vivem [...] Lendo e relendo Paulo Freire nos demos ainda mais conta de que para assumir uma prática de educação problematizadora, libertadora, não basta querer. É preciso muita disposição de aprender e de fazer autocrítica. É preciso ir refletindo sobre cada ação e se reorientando junto com outros educadores e com os educandos. É preciso superar a cultura da educação bancária que ainda é muito forte entre nós [...] Aprendemos com Paulo Freire que outro elemento fundamental da educação libertadora é a reflexão sobre a ação. Não basta pensar; não basta fazer. É preciso pensar sobre o que se faz e sobre o que se vive para poder assumir uma postura crítica diante do processo. E, para Freire, sem esta inserção crítica não há libertação verdadeira dos oprimidos.

Muitas categorias de Paulo Freire foram utilizadas como base para a pedagogia do MST. Aqui buscaremos destacar algumas delas, consideradas as mais proeminentes nos documentos do MST referentes à educação. Sendo elas: conscientização; educação libertadora; emancipação humana; gestão democrática; mudança/transformação social; oprimido/opressor; realidade; e temas geradores. Essas não são, obviamente, as únicas categorias freirianas presentes na pedagogia do MST, porém, são as que mais se destacam nos documentos do Movimento.

Quanto à categoria de conscientização, esta é compreendida como o processo de criticização das relações consciência-mundo; é o compromisso com a realidade, sendo esta uma possibilidade. A conscientização vai além da tomada de consciência, ela exige o engajamento nas ações transformadoras da realidade, "implica não apenas a consciência da realidade, mas também o engajamento na luta para transformá-la” (FREITAS, 2019, p. 105). Para Freire (2019) a conscientização possibilita ao homem e à mulher inserir-se no processo histórico como 
sujeitos. Na "verdadeira aprendizagem os educandos vão se transformando em reais sujeitos da construção e da reconstrução do saber ensinado, ao lado do educador, igualmente sujeito do processo" (FREIRE, 2020, p. 28).

Kimieciki (2019) afirma que a educação libertadora, segunda categoria aqui apresentada, se funde na perspectiva de se contrapor à educação bancária, que serve de instrumento à opressão. Segundo o autor, Freire busca afirmar a natureza da educação como ato político, como possibilidade: a relação desta com a transformação social. A educação libertadora estabelece os princípios da preparação para a mudança social, e uma metodologia coerente para que isso ocorra (KIMIECIKI, 2019) A educação libertadora pressupõe em si mesma a busca pela liberdade e pela autonomia, pela mudança e pela transformação sociais. Ela "funda-se justamente na relação dialógico-dialética entre educador e educando, ambos aprendem juntos" (GADOTTI, 1996, p. 86). Para Freire e Shor (1986) a educação libertadora não se faz com propostas apenas técnicas para se chegar à qualificação profissional; os métodos da educação libertadora, ao contrário, trazem a intimidade da sociedade, a razão de ser de cada objeto de estudo. Através dela busca-se ver as razões para que determinado momento seja assim e qual o contexto político e histórico em que está inserido. É, antes de mais nada, um ato de conhecimento e não mera e simples transferência de conhecimentos. "A educação libertadora não é um manual de habilidade técnica, é antes, porém, uma perspectiva crítica sobre a escola e a sociedade, o ensino voltado para a transformação social" (FREIRE e SHOR, 1986, p. 25). Freire e Shor (1986) ainda destacam que uma das características da educação libertadora é o estímulo à crítica que ultrapassa os muros da escola. "Isto é, em última análise, ao criticar as escolas tradicionais, o que devemos criticar é o sistema capitalista que modelou essas escolas" (FREIRE e SHOR, 1986, p. 48).

A emancipação humana é uma categoria que perpassa a obra de Paulo Freire, e é compreendida como uma grande luta ininterrupta a favor da libertação de homens e mulheres da dominação e opressão a que são submetidos; é a luta pela libertação e reconstrução da humanidade dos oprimidos (MOREIRA, 2019, p. 181). "O processo emancipatório freiriano decorre de uma intencionalidade política assumida e declarada por todos aqueles que são comprometidos com a transformação das condições e situações de vida e existência dos oprimidos (MOREIRA, 2019, p. 181)", levando-os à conscientização da necessidade de lutarem por sua autonomia. Para Paulo Freire a emancipação é "tarefa fundamental no ato de educar, ligada a outros princípios basilares da prática educativa, seria fundamentalmente a autonomia do direito pessoal na construção de uma sociedade democrática que a todos respeita e dignifica" (MACHADO, 2019, p. 61). Freire compreende a autonomia como o processo de "libertar o ser humano das cadeias do determinismo neoliberal, reconhecendo que a história é um tempo de possibilidades" (Ibid., p. 61). Freire, segundo Machado (2019), entende que a emancipação humana se trata de um processo de humanização e de decisão que vai sendo construído historicamente; a "autonomia é experiência da liberdade" (Ibid., p. 61). Para Fiori (2019) a emancipação humana está basicamente na ideia principal de que a educação não pode ser prática de dominação, ou seja, "a prática da liberdade só encontrará adequada expressão numa pedagogia em que o oprimido tenha condições de, reflexivamente, descobrir-se e conquistar-se como sujeito de sua própria destinação histórica" (Ibid., p. 11).

Segundo Lima (2019) a temática da gestão democrática, quarta categoria freiriana aqui exposta, está presente na obra de Paulo Freire desde seus primeiros escritos. Lima (2019) afirma que "pode-se, pois, falar de uma concepção freiriana de gestão democrática, ancorada nas críticas que produziu às perspectivas mecanicistas, racionalistas e burocráticas da educação" (LIMA, 2019, p. 236). Essa concepção freiriana de gestão democrática pode ser definida como transformação radical nas máquinas burocráticas, descentralização das decisões e democratização dos poderes educativos, e assunção de maior autonomia por parte das escolas; sustentadas numa visão antiautoritária da educação (LIMA, 2019, p. 236). "Em Freire, o 
problema da gestão democrática da educação é de ordem político-administrativa e pedagógica, e não uma questão técnico-gerencial" (LIMA, 2019, p. 236), transformando a escola num "locus de cidadania crítica e de produção colegial de orientações e regras próprias, em direção ao seu autogoverno" (LIMA, 2019, p. 236).

Weyh (2019) afirma que, para Paulo Freire, a categoria mudança/transformação social assume um caráter de comprometimento e engajamento nas lutas em favor das causas dos oprimidos. O autor destaca que transformação social, segundo Freire, vai muito além de reformas, estando condicionada a uma mudança estrutural de sociedade (Ibid.). A transformação social na perspectiva freiriana parte da ideia de que a mudança deve ser estrutural e alterar significativamente a sociedade, não podendo tratar apenas de reformas que alterem determinados aspectos, mas não alterem a estrutura que permite a existência da necessidade dessas reformas. Transformação social, para Freire, pressupõe uma sociedade justa e igualitária, sem divisões ou diferenciações, sem opressores e sem oprimidos.

Oliveira (2019) afirma que a categoria oprimido e opressor representa os dois polos opostos das relações sociais de antagonismo, onde "fundamentalmente, oprimidos e opressores são classes sociais antagônicas e em luta" (OLIVEIRA, 2019, p. 345). Há, basicamente, duas classes, as que oprimem e as que são oprimidas. As que dominam e as que são dominadas. Para Freire (2019a) é de suma importância que a educação se posicionasse ao lado dos oprimidos na tentativa de transformar essa realidade e acabar com os sistemas de dominação de uma classe sobre a outra. Freire (2019, p. 45) afirma que

É importante enfatizar que há uma diferença fundamental entre quem se acomoda perdidamente desesperançado, submetido de tal maneira à asfixia da necessidade, que inviabiliza a aventura da liberdade e a luta por ela, e quem tem, no discurso da acomodação, um instrumento eficaz de sua luta - a de obstaculizar a mudança. O primeiro é o oprimido sem horizonte; o segundo, o opressor impenitente.

Quanto à categoria realidade, para Freire esta não é apenas o fato concreto, o dado objetivo, mas também a percepção que o homem e a mulher têm dela. "Trata-se de ler a realidade para transformá-la" (GADOTTI, 2019, p. 399). A realidade para Freire está formada por partes que compõem um todo maior, e que devem ser consideradas, conhecidas e analisadas para sua transformação. Realidade, na perspectiva freiriana, não trata apenas do que os olhos podem ver ou do que as mãos podem tocar, mas do que está para além do visível e próximo, a estrutura maior que mantém essa realidade. Assim, a realidade não é dada, não é definitiva, mas sim possibilidade (FREIRE, 2019).

Segundo Passos (2019) os temas geradores, nossa última categoria de análise aqui presente, para Paulo Freire, são a procura no universo da comunidade de "lugares" repletos de sentido e de experiências para, a partir deles, construir o conhecimento. É a busca na realidade dos educandos e educandas dos temas que se farão análise e conhecimento. "Há nessa escuta um aprendizado e uma opção política de se deixar surpreender pela vida e pelas experiências humanas, sobretudo aquelas que reincidem das dores, reiteradas pelas falas, que emergem nos discursos" (PASSOS, 2019, p. 449). Para Passos (2019, p. 449) o tema gerador "sustenta o estudo, a reflexão pessoal e coletiva a partir da história vivida, sofrida". E podemos perceber que é partindo da realidade do educando e da educanda como tema gerador que se constrói o processo de ensino-aprendizagem para Paulo Freire e para a pedagogia do MST. "A teoria do conhecimento que parte da prática concreta na construção do saber, o educando como sujeito do conhecimento" (GADOTTI, 1996, p. 100).

À parte, categorias isoladas, a perspectiva pedagógica freiriana está presente na pedagogia do MST principalmente em um aspecto: a crença na educação como base para a construção de uma nova sociedade. Gadotti (1996) afirma que Freire procura mostrar qual o 
papel da educação, do ponto de vista do oprimido, na construção de uma nova sociedade. Ou, nas palavras do próprio Freire (2020b, p. 102):

Quando a gente encarna e vive este não estar só no mundo, está falando da metodologia popular. Esse modo de ver e de tratar é muito mais que um método - é uma concepção de mundo. É uma pedagogia. Pedagogia, e não um método cheio de técnicas. A gente sabe muito mais as coisas quando aprende o significado dessa pedagogia do que quando se aplica uma técnica. As técnicas só se encarnam quando o princípio é respeitado. Se o educador está disposto a viver com o educando uma experiência na qual o educando diz sua palavra ao educador, e não apenas escuta a palavra do educador, a educação se autentica, tendo no educando um criador de sua aprendizagem. Esse é um princípio fundamental.

Gadotti (1996, p. 84) ainda afirma que

Para ele (Paulo Freire), essa sociedade não pode ser construída pelas elites porque elas são incapazes de oferecer as bases de uma política de reformas. Essa nova sociedade só poderá se constituir como resultado da luta das massas populares, as únicas capazes de operar tal mudança. Paulo Freire entende que é possível engajar a educação nesse processo de conscientização e de movimento de massas.

Para o Movimento Sem Terra o processo ocorre do mesmo modo. O MST demonstra acreditar que uma nova sociedade só poderá surgir como fruto da luta das massas populares, como fruto da militância e da consciência que se torna ação na busca da transformação social (MST, 2001). Assim como Paulo Freire, o MST corrobora a ideia de que a educação deve ser construída através de uma concepção libertadora, evidenciando seu papel "na construção de um novo projeto histórico" (GADOTTI, 1996, p. 100) sem opressores e oprimidos.

O Movimento segue a ideia de Freire (1984, p. 28-29) quando este afirma que

na medida em que compreendemos a educação, de um lado reproduzindo a ideologia dominante, mas, de outro, proporcionando, independentemente da intenção de quem tem o poder, a negação daquela ideologia (ou seu desvelamento) pela confrontação entre ela e a realidade (como de fato está sendo e não como o discurso oficial diz que ela é), realidade vivida pelos educandos e pelos educadores, percebemos a inviabilidade da educação neutra.

Observa-se assim que para Freire (1984, p. 26) o mito da neutralidade da educação leva a uma prática educativa ingênua que serve aos interesses das forças dominantes, por isso, para ele e também para o MST, seria impossível negar o caráter político do processo educativo. Por isso, o MST (2008) afirma enfaticamente que sua educação é política e sua ação política é educativa. Ambas se fundam em alicerces para a construção/reconstrução da sociedade, para a transformação social, econômica e cultural (MST, 2008).

Posto isso, na educação, o MST demonstra utilizar a realidade como base da produção de conhecimento, não apenas restrita ao que os cerca, ao que vivem ou enxergam e sim ao mundo, partindo do assentamento ou acampamento como base; criando assim princípios metodológicos diferentes dos tradicionais. A realidade é além de ponto de partida, ponto de chegada: a transformação dessa realidade. No MST isto é feito através de temas geradores, que são questões extraídas da realidade, em torno das quais se desenvolve uma unidade de estudos, com conteúdos, didáticas e práticas concretas dos educandos e educandas, todas integradas. 
Segundo o MST, parte-se da realidade já conhecida dos estudantes e ir ligando-a com novas informações, estudos e discussões, chegando à realidade nacional e mundial (MST, 2001). Essa escolha não é feita de forma neutra, segundo o MST (2001, p. 15) "ela tem a ver com nossos objetivos educacionais mais amplos. Se dizemos: conteúdos formativos socialmente úteis, é porque no nosso entendimento, nem todos os conteúdos são igualmente formativos e nem todos são socialmente úteis". Segundo o MST (2001, p. 15)

Trata-se de utilizar o princípio da justiça social também nesta dimensão, ou seja, selecionar conteúdos que estejam na perspectiva da distribuição igualitária dos conhecimentos produzidos pela humanidade [...] que tenham a potencialidade pedagógica para educar os cidadãos e cidadãs da transformação social.

Neste ponto o MST destaca que em sua educação há um vínculo orgânico entre processos educativos e processos políticos; "tudo que fazemos é político" (MST, 2001, p. 16) pois encontra-se inserido em um "jogo de forças sociais que disputam o poder no conjunto da sociedade" (MST, 2001, p. 16). Para o MST (2001, p. 17) "a educação é sempre uma prática política, à medida que se insere dentro de um projeto de transformação ou de conservação social".

Para o MST (2001, p. 17):

Vínculo orgânico entre educação e política significa fazer a política entrar/atravessar os processos pedagógicos que acontecem nas escolas, nos cursos de formação. É bem mais, então, do que conversar sobre questões políticas. É conseguir trabalhar pelo menos algumas das seguintes dimensões:

a) Alimentar a indignação ética diante das situações de injustiça e de indignidade humanas. Ou seja, não podemos perder a sensibilidade frente à lógica da violência, da exclusão, da impunidade que está sendo imposta pelo modelo de sociedade atual [...] além disso, é preciso canalizar esse sentimento de indignação para o despertar da necessidade de mudanças, tanto na sociedade como em cada pessoa ou em cada um de nós;

b) Desenvolver atividades e estudar conteúdos voltados intencionalmente à formação político-ideológica dos/das estudantes[...];

c) Estimular e participar junto de lutas sociais concretas de outros trabalhadores de outras categorias, como forma de educar para a solidariedade de classe;

d) Incentivar os/as estudantes para que se organizem e aprendam também a lutar pelos seus direitos[...];

e) Desenvolver processos de crítica e autocrítica coletiva e pessoal, visando avançar na coerência entre o discurso político e a prática política [...];

f) Chegar a ser militante! Esta é a meta, porque nada mais efetivo no aprendizado político do que pertencer a uma organização. Pertencer a uma organização é assumir seu caráter, seus princípios, seus objetivos, e estar disposto a realizar as tarefas que lhe são confiadas[...] esta é, sem dúvida, uma dimensão fundamental de uma educação que se pretenda comprometida com a transformação social. E será tanto mais pedagogicamente eficaz, se for compartilhada por educadores/educadoras e educandos/educandas.

O principal pilar da educação do MST é a educação para a transformação social. Segundo o Movimento, seu compromisso histórico é explícito; fazendo parte da classe trabalhadora visa chegar à transformação radical da sociedade, contribuindo para a restauração da dignidade humana (Ibid). Ainda segundo o MST (2001, p. 140-141) 
Isto quer dizer, que nossa escola deve se colocar a serviço de um projeto político popular, garantindo no seu currículo: $1^{\circ}$ ) conteúdos críticos nas várias disciplinas, na perspectiva da conscientização política e formação ideológica dos jovens e da comunidade escolar; $2^{\circ}$ ) métodos de ensino que permitam aos alunos expressar suas ideias, questões, posições, desenvolvendo habilidades de expressão, de discussão, de argumentação, educando sujeitos; $3^{\circ}$ ) atividades político-culturais diversas que trabalhem o conjunto da comunidade, ajudando na construção da identidade cultural dos assentados ou de outros trabalhadores rurais envolvidos; $\left.4^{\circ}\right)$ a presença sistemática de dirigentes do MST e de outros Movimentos Populares, para participar de algumas aulas e atividades político-culturais, socializando seus conhecimentos sobre a luta, a conjuntura nacional, internacional, a produção...

Podemos concluir, após essas afirmações, que o MST se coloca ao lado da classe trabalhadora, enfatizando que sua educação é política e que seu projeto é popular. Em seu Caderno de Educação Número 1 - Como fazer a escola que queremos, o MST destaca que sua pedagogia "quer mudar o jogo e virar a escola tradicional de ponta cabeça" (MST, 1991, p. 13). E é esse objetivo o ponto forte de sua pedagogia.

\section{Considerações finais}

Tendo em vista o que foi descrito acima, podemos perceber que, assim como Paulo Freire, o Movimento Sem Terra acredita que não é possível alcançar a transformação social se a prática educativa se disser e se fizer neutra; a prática educativa exige uma definição, uma tomada de posição, uma decisão. Tendo consciência de que a neutralidade da educação é uma farsa, o MST, ao criar sua pedagogia, se posiciona firmemente ao lado dos oprimidos e destaca fortemente a presença política e o interesse pela transformação social em sua educação.

O MST se propôs a criar sua própria Pedagogia, desvinculando os interesses do capital na escola e criando meios e caminhos para criar uma escola e uma pedagogia críticas, problematizadoras e intencionalmente ligadas à luta de classes, colocando-se ao lado do proletariado e dos camponeses. Uma pedagogia para a transformação social, uma pedagogia para problematizar os sistemas de opressão e exploração, uma pedagogia para intervir no mundo - usando aqui a expressão de Paulo Freire. A cultura dominante e uma pedagogia dominante, pertencente a quem domina, não pode ser o caminho para a libertação do homem e da mulher oprimidos e oprimidas. É preciso uma pedagogia do oprimido, não para o oprimido. Uma pedagogia pertencente ao oprimido e construída com ele; uma pedagogia que parta de sua realidade e traga soluções para os problemas dessa realidade. Uma pedagogia que conscientize e que auxilie na transformação social e na busca por justiça social.

Acreditando na possibilidade de construção de uma sociedade igualitária e com justiça social, é de suma importância que a docência e a escola sejam um foco de resistência, que as aulas se tornem o local de construção da criticidade necessária aos educandos e educandas, que a educação se torne um meio para edificar a transformação social e estrutural, que vá além das meras reformas. É preciso que educadores e educadoras se munam da teoria necessária para tornar sua prática ferramenta de desconstrução da hegemonia da classe dominante, que ao dominar economicamente, domina também a educação, a cultura, os comportamentos, etc. A educação não pode se privar da carga que carrega nessa batalha de construção de uma nova sociedade; é sabido que ela sozinha não fará o trabalho todo, mas há a certeza de que sem ela não haverá transformação alguma.

\section{Referências}


BRITO, Nilza Bispo et al. MST: a pedagogia freiriana a favor da formação do Sem Terra. 2008. Disponível em: http://acervo.paulofreire.org:8080/xmlui/handle/7891/4237. Acesso em: 04 out. 2020.

FIORI, Ernani Maria. Aprender a dizer a sua palavra. In FREIRE, Paulo. Pedagogia do Oprimido. São Paulo: Paz e Terra, 2019. p. 11-30.

DALMAGRO. Sandra Luciana. A Escola no contexto das lutas do MST. Disponível em: https://repositorio.ufsc.br/handle/123456789/94587. Acesso em 10/10/2020.

FREIRE, Paulo. A importância do ato de ler: em três artigos que se completam. São Paulo: Autores Associados: Cortez, 1984.

FREIRE, Paulo; SHOR, Ira. Medo e Ousadia: o cotidiano do professor. São Paulo: Paz e Terra, 1986.

FREIRE, Paulo. Ação cultural para a liberdade. 9. ed., Rio de Janeiro, Paz e Terra. 2001.

FREIRE, Paulo. Extensão ou comunicação? 11. ed. Rio de Janeiro: Paz e Terra, 1983.

FREIRE, Paulo. Pedagogia da autonomia: saberes necessários à prática educativa. São Paulo: Paz e Terra, 2020.

FREIRE, Paulo. Pedagogia da Indignação: cartas pedagógicas e outros escritos. São Paulo: Paz e Terra, 2019.

FREIRE, Paulo. Princípios do trabalho popular. In: MST. Paulo Freire e a pedagogia do trabalho popular. Boletim da Educação no 15. São Paulo: 2020a.

FREITAS. Ana Lucia Souza de. Conscientização. In: STRECK, Danilo R. REDIN, Euclides. ZITKOSKI, Jaime José (Orgs.). Dicionário Paulo Freire. 4. ed. Belo Horizonte: Autêntica Editora, 2019. p. 104-106.

GADOTTI, Moacir. Paulo Freire: uma biobibliografia. São Paulo: Cortez, 1996.

GADOTTI, Moacir. Realidade. In: STRECK, Danilo R. REDIN, Euclides. ZITKOSKI, Jaime José (Orgs.). Dicionário Paulo Freire. 4. ed. Belo Horizonte: Autêntica Editora, 2019. p. 398400 .

GONSAGA, Eliana Aparecida. A educação no MST e sua relação com a perspectiva freiriana. In: ENCONTRO INTERNACIONAL DO FÓRUM PAULO FREIRE. 6., 2008. Disponível em http://acervo.paulofreire.org:8080/xmlui/handle/7891/4165 . Acesso em: 04 out. 2020.

JESUS, Sonia Meire Santos Azevedo de. As múltiplas inteligibilidades na produção dos conhecimentos, práticas sociais e estratégias de inclusão e participação dos movimentos sociais e sindicais do campo. P. 50-59. in MOLINA, Mônica Castagna. Educação do Campo e Pesquisa - Questões para reflexão - Brasília: Ministério do Desenvolvimento Agrário MDA, 2006. 
KIMIECIKI. Domingos. Educação Libertadora. In STRECK, Danilo R. REDIN, Euclides. ZITKOSKI, Jaime José (Orgs.). Dicionário Paulo Freire. 4. ed. Belo Horizonte: Autêntica Editora, 2019. p. 165-167.

LIMA, Licínio C. Gestão democrática. In: STRECK, Danilo R. REDIN, Euclides. ZITKOSKI, Jaime José (Orgs.). Dicionário Paulo Freire. 4. ed. Belo Horizonte: Autêntica Editora, 2019. p. 236-237.

MACHADO, Rita de Cássia de Fraga. Autonomia. In: STRECK, Danilo R. REDIN, Euclides. ZITKOSKI, Jaime José (Orgs.). Dicionário Paulo Freire. 4. ed. Belo Horizonte: Autêntica Editora, 2019. p. 61.

MOREIRA, Carlos Eduardo. Emancipação. In STRECK, Danilo R. REDIN, Euclides. ZITKOSKI, Jaime José (Orgs.). Dicionário Paulo Freire. 4. ed. Belo Horizonte: Autêntica Editora, 2019. p. 181, 182.

MST. Dossiê MST Escola: Documentos e estudos 1990-2001. Caderno de Educação no 13. Veranópolis, RS: ITERRA: 2005.

MST. Princípios da educação no MST. Caderno de educação nº 08 São Paulo: Setor de Educação, 2001.

MST. Paulo Freire e a pedagogia do trabalho popular. Boletim da Educação $\mathbf{n}^{0} \mathbf{1 5}$. São Paulo: 2020.

OLIVEIRA, Avelino da Rosa. Oprimido /Opressor. In: STRECK, Danilo R. REDIN, Euclides. ZITKOSKI, Jaime José (Orgs.). Dicionário Paulo Freire. 4. ed. Belo Horizonte: Autêntica Editora, 2019. P. 345-346.

PASSOS, Luiz Augusto. Tema gerador. In: STRECK, Danilo R. REDIN, Euclides. ZITKOSKI, Jaime José (Orgs.). Dicionário Paulo Freire. 4. ed. Belo Horizonte: Autêntica Editora, 2019. p. 447-449.

POLI, Odilon Luiz. Leituras em Movimentos Sociais. Chapecó: Grifos, 1999.

RECK, Jair. A consciência política dos cooperados do MST: o caso da COOPAC - campo verde-MT. 2005. Disponível em http://repositorio.unicamp.br/jspui/handle/REPOSIP/252462. Acesso em 11 dez. 2020.

STRECK, Danilo R. REDIN, Euclides. ZITKOSKI, Jaime José (Orgs.). Dicionário Paulo Freire. 4. ed. Belo Horizonte: Autêntica Editora, 2019.

WEYH, Cênio. Mudança/transformação social. In: STRECK, Danilo R. REDIN, Euclides. ZITKOSKI, Jaime José (Orgs.). Dicionário Paulo Freire. 4. ed. Belo Horizonte: Autêntica Editora, 2019. 